\section{Alimentación saludable en Shanghái: notas exploratorias}

\section{Healthy eating in Shanghai: exploratory notes}

\author{
Máximo Badaró \\ 'Doctor en Antropología Social. Investigador del Consejo \\ Nacional de Investigaciones Científicas y Técnicas (CONICET), \\ con sede en el Instituto de Altos Estudios Sociales, Universidad \\ Nacional de San Martín, Buenos Aires, Argentina. $\square$ (ID)
}

Es difícil que un visitante extranjero en China sea indiferente a la comida de este país. Lo primero que Ilama la atención no es el exotismo culinario que tanto atrae las miradas mediáticas y turísticas sobre China, sino más bien la omnipresencia de la comida en el espacio urbano: las calles están repletas de restaurantes de todo tipo y tamaño, mercados de productos frescos, animales y peces vivos, puestos callejeros y vendedores ambulantes. Esta omnipresencia también es discursiva y visual: la comida ocupa un lugar protagónico en las conversaciones informales y en los comentarios e imágenes que se intercambian a través de los medios de comunicación digitales y las redes virtuales.

Estos discursos sobre la comida giran principalmente en torno a la estética y los sabores de platos y productos, así como a la ubicación y ambientación de los lugares para comer. Hao kan, hao che (literalmente, "si es lindo, es delicioso") es una expresión muy frecuente en China, que indica la importancia que las personas asignan al valor estético de los alimentos a la hora de definir su valor gustativo y el atractivo para consumirlos.

En la actualidad, los discursos sobre la comida en China también prestan cada vez más atención a sus orígenes geográficos y modos de producción, su calidad, y los beneficios y peligros para la salud. Si bien es sabido que en China, como en otros lugares del mundo, la comida es percibida al mismo tiempo como alimento y medicina, en las últimas décadas, a raíz de los numerosos escándalos bromatológicos, la comida remite cada vez más a las ideas de impureza, artificialidad, contaminación y enfermedad ${ }^{(1,2)}$. Para Wang el interés por la "seguridad" de los productos es más importante que el "deseo" como motor del consumo en China ${ }^{(3)}$.

En el 2015, los discursos sociales sobre los riesgos bromatológicos marcaron mi experiencia cotidiana durante los seis meses que pasé en Shanghái haciendo trabajo de campo antropológico. No era la primera vez que visitaba China y nunca había prestado mucha atención a los discursos vinculados a la calidad de los alimentos y los aspectos bromatológicos. Pero en esa oportunidad viajé con mi pareja y mi hijo, que cumplió un año a los pocos días de haber Ilegado a Shanghái. Esta situación personal hizo que las diferentes dimensiones de la omnipresencia material y discursiva de la comida en China se impusieran no solo como una curiosidad antropológica y un factor de disfrute culinario, sino como una ocupación y una preocupación central de la experiencia cotidiana como padre de un niño que en aquel tiempo empezaba a comer alimentos sólidos con mayor frecuencia.

Estas necesidades de la paternidad también me conectaron desde un lugar más personal y vivencial con la centralidad que poseen las temáticas vinculadas a la crianza de los niños en la sociedad china actual, en particular, los temas de salud, alimentación y educación, sobre las cuales solo había leído pero no las había experimentado personalmente. Rápidamente me di cuenta de que el hecho de vivir con un niño pequeño en Shanghái me posibilitaba generar diálogos muy espontáneos con las personas que encontraba en los lugares públicos que visitaba con mi hijo (parques, transporte público, mercados, comercios, restaurantes) y con otras personas chinas que encontraba en la universidad en la que estaba radicado o en los lugares donde realizaba trabajo de campo.

En estos diálogos, la problemática de la calidad de los alimentos y los riesgos bromatológicos ocupaba un lugar dominante. 
Cuando mis interlocutores eran otros "extranjeros" viviendo en China con niños pequeños y cuando leía publicaciones destinadas al público de expatriados, la mención a esta problemática se veía potenciada a niveles de paranoia alimentaria. Cuando les preguntaba qué hacer para paliar esta situación en la crianza de niños pequeños en Shanghái, mis interlocutores chinos y extranjeros invariablemente me daban la misma respuesta: recurrir a productos frescos, orgánicos e importados que podían encontrarse en sectores especiales de los grandes supermercados de cadenas internacionales (Walmart, Carrefour) o supermercados de productos premium importados (CityShop, City Super, Olé, Fresh Mart), comprar en Internet cajas de frutas y verduras que provienen de huertas orgánicas en China e ir a restaurantes de comida orgánica y "saludable".

En Buenos Aires, nunca le había prestado mucha atención a los temas vinculados con la calidad de los alimentos y menos aún a los productos "orgánicos". Pero en Shanghái, mi encuentro con los discursos públicos e informales sobre los alimentos, la alimentación y los problemas bromatológicos, las alarmas y temores que generan estos discursos, y la necesidad práctica de alimentar a mi hijo, me Ilevaron a prestar atención al universo de productos, instituciones, imágenes y discursos relacionados con la llamada "alimentación saludable" y los productos orgánicos y ecológicos en esta ciudad. Durante los meses que pasamos en Shanghái mi hijo probó y comió de todo. Su consumo de frutas y verduras etiquetadas como "orgánicas" se alternaba con las que comprábamos en cualquier mercado a cielo abierto a vendedores que, en muchos casos, viajaban a la ciudad desde la periferia urbana o zonas peri-rurales para ofrecer sus productos.

Si bien nuestras prácticas alimentarias no respetaron al pie de la letra los consejos de mis interlocutores sobre la alimentación de los niños en Shanghái y los riesgos bromatológicos en China, lo cierto es que esta temática marcó nuestra estadía en esa ciudad. Pero siempre se trató de una temática de mi vida cotidiana y familiar en Shanghái que hasta ese momento estaba alejada de los temas e intereses de investigación que me habían llevado a este país: el estudio de la riqueza y el consumo en China y, en particular, el impresionante crecimiento del consumo de marcas de lujo extranjeras, así como las prácticas e ideas de los profesionales del marketing que trabajan para estas marcas en este país.

Sin embargo, a medida que fui avanzando en esta investigación, que yo había comenzado en 2014, con 20 días de trabajo de campo exploratorio en Pekín y Shanghái, comencé a encontrar que la temática de la riqueza y el lujo tenía fuertes conexiones con la problemática alimentaria en China y las preocupaciones y los discursos sociales sobre la calidad de los alimentos y las cuestiones bromatológicas. Encontré que el marketing del lujo en China ponía énfasis no tanto en la ostentación material del producto de lujo como en su capacidad para contribuir al cultivo del bienestar personal. El tipo de experiencia que estos bienes están Ilamados a ofrecer se juega tanto en el plano de su materialidad como también en el plano de los valores que las marcas internacionales intentan asociar a estos productos: originalidad, autoría, artesanía, calidad y pureza. Los bienes de lujo extranjeros forman parte de un creciente mercado del bienestar individual y del cuidado personal (corporal y espiritual) que apunta a construir nuevas subjetividades a través de la conexión de las personas con prácticas, lugares, productos e ideas que los actores involucrados buscan asociar con lo natural, puro, espiritual y auténtico. Y aquí la alimentación ocupa un lugar protagónico.

Así, mi interés en el marketing del lujo en China me llevó hacia el marketing de la alimentación saludable en Shanghái, para lo cual realicé una investigación exploratoria de un mes entre julio y agosto de 2016, que incluyó entrevistas y charlas informales con dueños y gerentes de restaurantes que se autodefinen como "orgánicos" o de alimentación "saludable", dueños de páginas web que ofrecen productos etiquetados como orgánicos o naturales, la visita a una huerta de producción "natural" de verduras y hortalizas en la isla de Chongming, a dos horas 
de Shanghái, la visita a restaurantes y la consulta de páginas web, aplicaciones de celular y foros virtuales dedicados a esta temática en China. Cabe aclarar que, en este texto, si bien utilizo nombres ficticios para mantener el anonimato de las personas, para los restaurantes y otros establecimientos he mantenido sus nombres reales.

Rubén, un amigo que vive hace 15 años en Shanghái y trabaja como importador de productos alimenticios a China, se rió cuando le comenté mi idea de explorar el mercado orgánico en Shanghái: "En China es imposible cultivar productos orgánicos, está todo contaminado", me dijo, repitiendo un razonamiento que escuché de muchas personas en este país, tanto chinas como extranjeras. Sin embargo, en la última década, China triplicó su producción orgánica y en la actualidad ocupa el cuarto lugar del mundo en términos de hectáreas dedicadas a cultivos orgánicos y sus diversas variantes, así como de consumo de estos productos, muchos de los cuales provienen del exterior, ya que este país es el principal importador mundial de productos orgánicos.

Por otra parte, el Estado chino posee sistemas gubernamentales de certificación orgánica y ecológica de productos agrícolas. A comienzos de la década de 1990, el Ministerio de Agricultura chino creó una certificación de "comida ecológica" (luse shipin, literalmente, "comida verde") para productos agrícolas reducidos en químicos, que estaba principalmente destinada al mercado local. Y luego creó una certificación de "comida orgánica" (youji shipin) que se aplica a productos domésticos e internacionales. Esta última certificación se aplica principalmente a productos del mercado de alimentos premium que se encuentran en grandes urbes como Pekín y Shanghái, mientras que el rótulo de "alimento ecológico" está ampliamente difundido en términos de cantidad de productos y ciudades ${ }^{(4)}$.

Si bien en China la producción y el consumo de productos orgánicos no supera el $1 \%$ de la producción agrícola y del mercado de consumo de alimentos, se trata de un mercado que no ha parado de crecer. De hecho, el importante aumento de inversiones de capitales chinos en la producción orgánica y ecológica dentro y fuera de China, sobre todo en Australia, Nueva Zelanda y EE.UU., el constante crecimiento de la importación china de estos productos y del interés de las clases medias y altas en una alimentación más saludable indica que este mercado continuará creciendo en los próximos años. A esto se agrega que los problemas bromatológicos y de contaminación medioambiental se han agravado, y que en la última década el gobierno chino ha colocado estos problemas en el centro de su agenda política. De hecho, el gobierno chino ha reconocido que el $40 \%$ de los ríos y el $20 \%$ de la tierra en China están seriamente contaminados ${ }^{(5,6)}$.

Las páginas que siguen presentan una descripción exploratoria de algunos escenarios de la alimentación saludable en Shanghái que han surgido y crecido a gran velocidad en la última década. Utilizo el término "alimentación saludable" como un concepto genérico para referirme a productos, lugares y prácticas catalogados como "saludables", "orgánicas", "ecológicas", "naturales", "bio", entre otras categorías.

En Shanghái, los escenarios de la alimentación saludable poseen una fuerte vinculación con actores, capitales, símbolos y registros culturales de origen extranjero, principalmente, estadounidenses, europeos y asiáticos. En los restaurantes y sitios de compra por Internet de productos orgánicos, lo extranjero aparece en el origen de los dueños, inversionistas, consultores, proveedores y expertos en marketing. También aparece en el origen de muchos productos, la estética de los lugares, los tipos de platos elaborados y la constante mezcla del idioma chino y el inglés.

Pero estas conexiones extranjeras no significan que estos lugares, y el mercado de la alimentación saludable, en general, estén únicamente dirigidos a la importante cantidad de extranjeros que residen en Shanghái. Por el contrario, en términos numéricos, la clientela de estos establecimientos está conformada mayoritariamente por personas que provienen de los sectores más cosmopolitas 
e internacionalizados de las clases medias y altas profesionales de la sociedad china. La capacidad de consumo de estos sectores está haciendo crecer a gran velocidad lo que podríamos denominar como "el mercado del bienestar individual" en las principales urbes chinas. Este mercado incluye actores, instituciones y actividades con fuertes conexiones globales vinculadas al cuidado del cuerpo, la espiritualidad, la alimentación, la formación cultural y la redefinición de las relaciones sociales y del vínculo con la naturaleza.

La alimentación es quizás el sector que expresa con mayor fuerza las lógicas sociales, políticas y culturales que movilizan el desarrollo del mercado del bienestar en China: la búsqueda de mecanismos para conjurar, paliar o redefinir simbólica y subjetivamente en el plano individual los efectos de las enormes transformaciones y de las complejas relaciones entre creación y destrucción que ha generado el vertiginoso crecimiento económico de China en las últimas dos décadas.

\section{RESTAURANTES SALUDABLES EN SHANGHÁI: ESTÉTICA, ALTERIDAD Y COMENSALIDAD}

Lo primero que llama la atención de los restaurantes, sitios web, plataformas virtuales y aplicaciones de celular vinculadas a la alimentación saludable en Shanghái es la centralidad que ocupa la dimensión estética y simbólica. La alimentación aparece allí, ante todo, como un campo discursivo y un régimen estético elaborado en torno a dos símbolos claves: la naturaleza y la alteridad. Estas dimensiones aparecen a primera vista en los nombres de la mayoría de los restaurantes que reivindican el carácter saludable u orgánico de la comida que sirven: "Element Fresh", "Hunter Gatherer", "Organic Kitchen", "Pure and Whole", Sprout Lifestyle", "The Urban Harvest", "Green and Safe".

Los nombres de estos restaurantes remiten la alimentación a un estado de naturaleza, sin referencias a tradiciones o imaginarios culturales ligados a la historia china. Se trata de una naturaleza que se expresa en otro idioma, sugiriendo así una asociación entre la pureza natural y lo extranjero. Este recurso discursivo y esta asociación de sentidos no son novedosas en China. En Shanghái es muy común ver que empresas y comercios chinos coloquen nombres en inglés a sus productos y a sus locales para beneficiarse de la buena reputación que detentan los productos importados entre los consumidores locales.

En los nombres de los restaurantes también aparece una dimensión central del régimen discursivo y estético que prevalece en la mayoría de las actividades relacionadas con la alimentación saludable en Shanghái: la naturaleza como ajenidad. El marketing de la alimentación saludable en China se nutre de la constante sospecha de los consumidores chinos respecto de la calidad de los alimentos producidos en China, los frecuentes escándalos de contaminación y adulteración de alimentos y los enormes problemas de contaminación ambiental.

Esto permite asociar a los alimentos considerados orgánicos y saludables con una naturaleza prístina alejada de las experiencias cotidianas de los consumidores chinos y, en términos generales, del medioambiente chino. De allí que, en China, el mercado de alimentos orgánicos y saludables tienda a estar asociado a productos, países, marcas y sabores extranjeros. Y esto se refuerza aún más en las estrategias de marketing de estos establecimientos, que buscan transformar la experiencia de consumo de estos productos en una experiencia de la alteridad.

En el menú de estos restaurantes predominan los productos, modos de preparación, presentación de los alimentos y nombres de platos que remiten a países extranjeros: wraps, falafel, hamburguesas, hummus, guacamole, quinoa, kale, diferentes tipos de hojas verdes, palta, picantes mexicanos, tortillas, nachos, pizzas, chucrut, muffins, cakes, ensalada César, jugos energizantes y desintoxicantes, currys tailandeses e indios y pastas al estilo italiano, entre otros. También abundan formas de preparación y presentación de los alimentos que están prácticamente ausentes de las múltiples expresiones 
y tradiciones de la cocina china y sus formas de consumo, como los platos con alimentos crudos (sobre todo en ensaladas), la estructura del plato principal o plato único, los postres y el formato del "brunch". Estos ingredientes y platos asociados con países y tradiciones culinarias extranjeras, muchas veces conviven con ingredientes y preparaciones que tienen mucho protagonismo en la cocina china: sopas, poroto negro, tofu, panceta, pollo, dumpling, arroz negro, fideos, maní, zapallo, té verde, cilantro, jengibre y diferentes tipos de hongos y pimientas, entre otros.

El diseño interior de estos restaurantes gira en torno a dos estéticas predominantes: por un lado, una estética minimalista de estilo nórdico con muebles de madera con tonalidades naturales y colores claros (blancos, grises y verdes claros), líneas finas o redondeadas y sin ornamentaciones en el diseño de los muebles, paredes lisas pintadas con colores claros, espacios amplios, ventanas grandes e iluminación discreta. En otros restaurantes la estética minimalista se combina con algunos elementos cercanos a una estética industrial o fabril que incluye cemento alisado en los pisos y paredes, vigas de hierro, mostradores o estantes de hierro, madera y vidrio, techos altos e iluminación focalizada. En algunos casos, los ambientes están decorados con plantas, cuadros con frases en inglés (vinculadas al bienestar y la salud) e imágenes de paisajes y, en otros, predomina el ascetismo estético de luces tenues y paredes blancas sin decoración.

En estos restaurantes, el principal decorado son los productos disponibles para el consumo en el lugar o para llevar. En la mayoría de estos establecimientos los ingredientes de los platos y los platos ya preparados se exhiben a la vista de los clientes en los mostradores principales. Muchos de ellos tienen un sector de mercado donde se venden frutas y verduras frescas que, en general, están dispuestas en cajones de madera y canastos de mimbre. También tienen pizarrones y carteles que indican los lugares de proveniencia de los productos frescos (muchos de estos restaurantes poseen sus propias huertas en las afueras de Shanghái), las técnicas con las que fueron cultivados y las fechas de cosecha. En este sector de mercado de los restaurantes también se venden otros productos que allí se presentan como orgánicos, naturales o ecológicos, generalmente de origen importado: vino, aceite de oliva, cereales, condimentos, conservas, salsas, y libros sobre alimentación saludable y recetas de cocina de diferentes lugares del mundo.

La forma y disposición de las mesas y sillas para comer son un indicador del tipo de comensalidad que estos lugares promueven. Aquí predominan las mesas comunales, largas y rectangulares, las mesas pequeñas para no más de dos personas o largos mostradores con taburetes altos para comensales individuales. Las mesas son, en general, angostas y poseen poco lugar para más de uno o dos platos por persona. La comensalidad privilegiada es la de individuos aislados que no se conocen entre sí o de parejas o pequeños grupos de amigos o compañeros de trabajo que no comen de los mismos platos sino que cada uno consume individualmente el plato elegido, y que no dedican mucho tiempo al acto de comer y a la sociabilidad en torno a la comida. Esta organización de la comensalidad difiere radicalmente de la de los restaurantes tradicionales de comida china, donde predominan las mesas redondas preparadas para albergar a familias extendidas de abuelos, padres, hermanos y niños. Estas mesas tienen lugar suficiente para muchos platos, vasos y botellas y predisponen a un consumo pausado de los alimentos y a una sociabilidad intensa entre los comensales.

A su vez, en los restaurantes chinos más tradicionales tiende a primar la abundancia y la exuberancia visual de alimentos y bebidas, muchos de los cuales quedan sin consumir al finalizar la comida. En estos casos, la escenificación del exceso del consumo de alimentos apunta a reflejar la riqueza económica de los comensales y busca conjurar las imágenes asociadas a experiencias de hambre y de escasez de alimentos que marcaron la vida de la población china durante el período maoísta. En los restaurantes saludables, en cambio, prevalece una escenificación minimalista de los alimentos en su cantidad y su estética. 
Mientras los restaurantes tradicionales se destacan por el ruido de las voces de los Comensales, su movilidad entre las mesas y una tendencia a ampliar la ocupación del espacio con sus cuerpos (recostándose en las mesas, desplazando las sillas u ocupando el piso con botellas, vestimentas y carteras), en los restaurantes saludables se destaca la tranquilidad de la música ambiente, las voces bajas de los comensales y una ocupación acotada del espacio que se ajusta al consumo individualizado de los alimentos y a la interacción de grupos pequeños.

En estos restaurantes, la estética que prima ya no es la de la abundancia y el exceso sino la de la moderación y el cuidado de sí. De esta manera, la mezcla, confusión e indefinición de ingredientes y sabores, la abundancia de salsas y aceites, los sabores intensos, las frituras y las diversas consistencias de los productos de la comida china tradicional, dejan lugar a platos de sabores simples y suaves, compuestos por ingredientes que pueden distinguirse claramente $y$ que están individualizados en términos de su nombre, origen y propiedades nutritivas.

La alimentación saludable en estos restaurantes exige un disciplinamiento corporal y emocional que está en sintonía con los programas actuales de "civilización" impulsados por el gobierno chino a través de afiches en las calles, publicaciones y programas televisivos que promueven el cuidado del cuerpo y la salud, y la educación de modales públicos y privados de los ciudadanos de este país. En la obsesión por la "calidad" de los alimentos y la alimentación que ponen en escena estos restaurantes resuenan también las obsesiones gubernamentales para mejorar la "calidad" (suzhi) moral de los ciudadanos ${ }^{(7,8)}$.

La mayoría de estos restaurantes se abrieron en los últimos 10 años y el rápido éxito comercial de algunos hizo que se inauguraran varias sucursales en los barrios de oficinas, comercios, hoteles y shopping malls más exclusivos de Shanghái, a los que concurren los sectores de poder adquisitivo medio-alto de esta ciudad, trabajadores expatriados y turistas. Los gerentes y dueños de estos comercios con los que hablé me comentaron que, en los primeros años, la "alimentación saludable" atraía principalmente a los extranjeros que vivían en Shanghái y a la importante comunidad de la diáspora china que ha "regresado" a China en los últimos años parar trabajar y hacer negocios (nacidos en China o hijos de chinos criados en el exterior), pero en los últimos años la clientela se compone principalmente de población local.

En las numerosas visitas que hice a estos restaurantes para comer y hacer entrevistas, pude identificar que la mayoría de los clientes eran mujeres chinas de entre 20 y 30 años que pertenecen a los sectores con mayor poder adquisitivo y mayor experiencia internacional (laboral, educativa, turística) de las clases medias-altas chinas, que en la última década han vivido un enorme crecimiento y diversificación tanto en tamaño y capacidad de consumo como en preferencias estéticas y culinarias $^{(9,10)}$.

En términos de género, esta composición responde, por un lado, al hecho de que en China, como en otros lugares del mundo, la alimentación y sus temáticas asociadas (elección de alimentos, cocina, salud, nutrición, crianza de los niños) suele recaer en las mujeres y, por otro, la "alimentación saludable" se enmarca en un conjunto de discursos y prácticas vinculadas al cuidado de sí y de la familia, en el que las mujeres poseen un rol protagónico. A esto se agrega que, a diferencia de los hombres chinos, las jóvenes chinas son quienes están más abiertas a las experimentaciones cosmopolitas ${ }^{(11)}$ en el plano de la alimentación y el ocio, las preferencias culturales y los estilos estéticos.

\section{PEDAGOGÍAS CULINARIAS}

La mayoría de los responsables de restaurantes y páginas web con los que hablé en Shanghái me dijeron que el mercado de la alimentación orgánica y saludable en China requiere mucho trabajo de "educación del consumidor" en diferentes aspectos: "concientización" sobre la importancia de la alimentación saludable para la salud de las 
personas y los beneficios de la producción de alimentos orgánicos para el medioambiente, la valoración de la calidad nutricional de los alimentos orgánicos, y el aprendizaje de los modos de preparación, combinación y apreciación del sabor de productos de otros países. Estos empresarios se refieren a la "educación del paladar" como una educación cultural que apunta a transformar el campo de la alimentación, tanto en un escenario de experiencias cosmopolitas como en un ejemplo emblemático del carácter global de los grandes centros urbanos de la China actual.

Pero esta impronta pedagógica también involucra una educación moral. Por un lado, la constante asociación de la alimentación saludable con productos, prácticas y sabores de origen extranjero contribuye a reforzar la idea ampliamente extendida en China de que los productos de "calidad" -sobre todo los alimentos- siempre provienen de otro país. Y esta "calidad" se concibe tanto en términos materiales como morales. Los numerosos escándalos de contaminación medioambiental y de alimentos, y la expansión de la industria de la falsificación han llevado a un fuerte cuestionamiento de los "valores" y la "calidad" moral de quienes están a cargo de la producción y comercialización de todo tipo de productos en China. La mayoría de las personas que conocí en Shanghái me comentaron que los consumidores chinos no confían en los productos nacionales porque no confían en los valores éticos de los empresarios chinos.

Estas representaciones morales del mercado de alimentos chino contribuyen a transformar la alimentación saludable en un mercado en el que no solo se producen, venden y consumen alimentos, sino también valores y representaciones morales acerca de productos, personas, lugares y prácticas. Los espacios de alimentación saludable en Shanghái construyen su legitimidad pública apelando a la confianza que despiertan en los consumidores chinos los productos, las personas y los saberes provenientes de algunas regiones del mundo (Australia, Canadá, EE.UU., Japón y Europa). Para ello, estos espacios, y los actores que están a su cargo, que en su mayoría son empresarios extranjeros radicados en Shanghái o hijos de chinos nacidos y criados en el extranjero, despliegan una pedagogía que apunta a enseñar propiedades y cualidades morales de los productos que ofrecen, de las personas que los venden y de los lugares de donde provienen, así como de las culturas, saberes y técnicas a los que estos productos están asociados.

Muchos menús y sitios web de estos restaurantes presentan una detallada descripción de los ingredientes que componen los platos que ofrecen, sus virtudes nutricionales, orígenes y modos de cultivo. Y también detallan las trayectorias biográficas de sus dueños o la historia y la filosofía del establecimiento. A modo de ejemplo, describiré en extenso el discurso institucional de Hunter Gatherer, un establecimiento que visité muchas veces en algunos de sus tres locales ubicados en los barrios comerciales y de oficinas más exclusivos Shanghái (y un local de próxima apertura en un conocido shopping mall de lujo) que, además, posee dos huertas propias en la isla de Chongming y en la provincia de Shandong.

El eslogan institucional que aparece en la web de Hunter Gatherer revela cómo este establecimiento concibe sus actividades: "Somos un ecosistema de la semilla a la mesa que sirve y celebra la comida verdadera". En Shanghái, una particularidad de los restaurantes y establecimientos como Hunter Gatherer es que se presentan como nodos de una red más amplia que incluye productores, distribuidores, vendedores y consumidores de productos alimenticios o como una red en sí misma que involucra a esta diversidad de actores y prácticas. Esta última modalidad es la de Hunter Gatherer que, en su caracterización como "ecosistema", apela a una perspectiva holística sobre la relación entre producción, distribución y consumo de alimentos y a metáforas sobre el orden de la naturaleza, para significar sus modalidades de organización institucional.

Por otra parte, la noción de "comida verdadera" que aparece en este eslogan institucional constituye una declaración moral sobre la constante sospecha que pesa sobre 
el mercado de la alimentación en China, a partir de la cobertura mediática nacional e internacional que han recibido los numerosos incidentes de "comida falsa" y adulteración de alimentos en la última década.

En la actualidad, la comida en China remite tanto al placer y la celebración como a sospechas y temores. La mayoría de las personas que conocí en Shanghái manifestaban esta ambivalencia respecto de la comida. Por un lado, mis interlocutores chinos en Shanghái (amigos, colegas, conocidos ocasionales y personas que entrevisté o que observé comiendo en diferentes ámbitos) siempre manifestaban un fuerte orgullo por la riqueza y la diversidad de la comida china (productos, tradiciones culinarias, sabores, texturas, colores y aromas). Pero, por otro lado, también reconocían en la comida producida en China una fuente de peligro y sospechas, vinculada no solo a la calidad nutricional de los productos, su origen o sus modos de producción, sino también a la autenticidad de su materialidad. En muchas ocasiones, en un restaurante o en un puesto de comida callejera, mis interlocutores me decían que no sabían si los ingredientes que figuraban en el menú o que anunciaba el vendedor eran realmente los que estábamos comiendo (sobre todo en relación con las carnes utilizadas como relleno de ravioles, en sopas o en saltados de arroz, fideos o pinchos a las brasas).

En este contexto, los establecimientos y actores relacionados con la alimentación saludable colocan la confiabilidad de sus productos y la honestidad de sus prácticas como el aspecto que los distingue respecto de otros establecimientos y actores del mercado de la alimentación en China. Así, en el sitio web de Hunter Gatherer ${ }^{(12)}$ se lee:

De la semilla a la mesa no es solo un eslogan. Es el fundamento de quiénes somos. Esto significa que servimos comida verdadera preparada con productos frescos y libres de químicos, cultivados en nuestras propias fincas. Cuando nos visitas para comer, queremos que sepas de dónde viene lo que estás comiendo. Creemos que alimentos de alta calidad quiere decir más que solo su sabor, los alimentos verdaderos deben ser cultivados naturalmente y beneficiar a todos, desde el agricultor hasta tu salud. [Traducción del original: "Seed-to-table isn't just a slogan at Hunter Gatherer-it's the bedrock of who we are. That means we serve real food made with fresh, chemical-free produce grown on our self-owned farms. When you join us for a meal, we want you to know where your food comes from. We believe high-quality food is about more than just taste; real food should be naturally raised and benefit everyone, from the farmer to your health"].

La construcción de confianza también es un componente central de la performance estética que caracteriza la organización simbólica y espacial de estos restaurantes ${ }^{(12)}$ :

Aquí creemos en ser honestos respecto de cómo nuestra comida llega desde las fincas hasta tu plato. Por eso nuestro restaurante tiene una cocina abierta donde podés observar a nuestros cocineros en acción. $Y$ este carácter abierto se extiende a nuestro comedor, instalado en una atmósfera limpia y contemporánea. [Traducción del original: "Here at Hunter Gatherer we believe in being honest about how our food moves from the farm to your plate. That's why our restaurant features an open kitchen, where you can watch our chefs and team members in action. That open character is extended to our dining area, set within a clean, contemporary atmosphere"].

Este fragmento pone en evidencia que el mercado de la alimentación saludable en China enfrenta un dilema comercial y moral: por un lado, necesita construir confiabilidad en un contexto nacional en el cual los productos de origen local cargan con fuertes sospechas de contaminación, artificialidad y adulteración; por otro lado, se trata de un mercado que busca distinguirse de la producción industrial de alimentos a través de la reivindicación de lo local y la pequeña escala como fuente de autenticidad, calidad y sustentabilidad económica y medioambiental de los alimentos y su producción. 
¿Cómo diferenciarse de China y reivindicar al mismo tiempo la producción local en China? Ante este dilema, Hunter Gatherer adopta una estrategia que es común a la de muchos otros actores de este mercado en China: no solo recurrir a productos cultivados y elaborados por ellos mismos sino también presentarse como intermediarios morales que garantizan la confiabilidad de los productos de otros actores. Esta estrategia aparece claramente en el modo en que Hunter Gatherer justifica los productos que venden en el sector de mercado que posee cada restaurante:

Desde chocolate proveniente del comercio justo hasta productos frescos traídos desde nuestras fincas libres de químicos, nuestro sector de mercado está repleto de productos confiables y completamente naturales que son consistentes con nuestra filosofía de la comida verdadera. Solo incluimos productos de terceros que pasan nuestros rigurosos estándares de control, por lo cual la mayoría de los productos que encontrarás provienen del extranjero, dado que en China la selección de productos confiables y naturales es actualmente muy limitada. Sin embargo, para nosotros es muy importante proveernos localmente, por lo cual estamos trabajando duramente para encontrar y apoyar productos domésticos. El objetivo para nuestro sector de mercado es ayudar a construir un sistema de alimentos más sustentable en Shanghái y más allá. [Traducción del original: From fair-trade chocolate to fresh produce delivered from our chemical-free farms, our marketplace is stocked with trusted all-natural products consistent with our real food philosophy. We only include third-party products that pass our stringent standards, which is why the majority of the items you see are sourced from abroad-the selection of reputable all-natural products in China is currently very limited. However, sourcing locally is very important to us and so we're working hard to search for and support trustworthy domestic products. Our goal for our marketplace is to help build a more local and sustainable food system in Shanghai and beyond].

\section{LA COCINA COMO EMPRENDIMIENTO MORAL}

Judy es una especialista en nutrición saludable y terapias naturales nacida en Australia, de padres chinos, que vive en Shanghái desde hace más de 15 años. En el 2013, ella y una colega china crearon en esta ciudad una empresa que actualmente combina, en sus dos locales, diferentes actividades vinculadas a la alimentación saludable: una escuela de cocina, un café, un comercio de productos alimentarios y un servicio de catering $y$ eventos. El eslogan institucional de la empresa es "Cultivando hábitos saludables". En julio de 2016, cuando hablé con ella en uno sus locales, Judy me dijo que todas las actividades de su empresa buscan crear espacios de aprendizaje y concientización sobre la relación entre alimentación y salud en China. Judy y un equipo de nutricionistas y cocineras chinas y extranjeras dictan clases de cocina de uno o varios días que introducen a las asistentes en el uso de ingredientes considerados saludables y que no tienen mucha difusión en China (sobre todo granos, brotes y alimentos crudos), así como en la preparación de platos que no forman parte de su dieta cotidiana (postres, desayunos con frutas, tortas dulces, jugos y licuados) y que provienen de otros países o que responden a principios de alimentación que no poseen mucha difusión en China (cocina vegana, vegetariana, detox, holística, naturista, macrobiótica). También hay cursos de cocina saludable para niños y para empleadas domésticas, entre otros.

Judy me comentó que la mayoría de las personas que asisten a estos cursos son mujeres menores de 30 años que quieren aprender nuevas formas de alimentación para su familia porque están preocupadas por los riesgos bromatológicos en China o porque buscan ampliar sus prácticas y gustos culinarios en clave cosmopolita y saludable. Pero Judy me aclaró que, más allá de estos motivos, muchas de ellas en realidad no poseen los conocimientos más rudimentarios de la cocina ni los usos de productos. De hecho, una de las características de las prácticas 
alimentarias de las generaciones más jóvenes de sectores medios-altos en China es que se basan en el consumo de productos industrializados que se calientan en la casa o solo requieren una preparación muy simple para su consumo, que la mayoría de sus comidas se hacen fuera de la casa en restaurantes y locales de comida rápida, o que la preparación de la comida está a cargo de empleadas domésticas, madres o abuelas que conviven con ellos. De allí que muchas veces los cursos de Judy se transforman en clases sobre los principios básicos de la cocina doméstica: cómo lavar, cortar y cocinar verduras y legumbres, cómo identificar puntos de cocción, cómo manipular productos frescos o cómo mantener la higiene y la organización en la cocina.

En agosto de 2016, como parte de mi investigación etnográfica sobre el marketing en China, acompañé a una consultora internacional en el desarrollo de un estudio de mercado sobre consumo de alimentos y bebidas que incluyó entrevistas y cenas con diez familias en sus casas y en restaurantes en diferentes barrios de Shanghái. En ese estudio observé las mismas tendencias que comentaba Judy acerca de las rupturas en la transmisión generacional de conocimientos sobre los alimentos y su preparación, así como en el escaso tiempo que las generaciones urbanas menores de 40 años dedican a la cocina en el ámbito doméstico. Para Judy, esta situación lleva a que los hábitos alimentarios de estas generaciones prácticamente no incluyan alimentos frescos y se concentren en alimentos ultraprocesados y en preparaciones rápidas como frituras, que son nocivas para la salud.

Judy dice que en China existen muchos productos y tradiciones culinarias saludables que son desconocidas por la mayoría de las generaciones más jóvenes. Por eso, me aclara que sus actividades pedagógicas sobre la alimentación no solo buscan "introducir" prácticas culinarias y productos saludables de origen extranjero en los hábitos alimentarios de los consumidores chinos, sino que su pedagogía culinaria también apunta a que estos consumidores "redescubran" ingredientes, productos y técnicas de preparación de alimentos propios de la historia culinaria de China, que han sido olvidados o son desconocidos en la actualidad por las generaciones de adultos jóvenes chinos.

Además de clases de cocina, la empresa de Judy también brinda muchos seminarios y cursos que conectan la alimentación con el bienestar corporal y espiritual: medicina tradicional china, terapias ayurvédicas y energizantes, yoga y técnicas de meditación, dietas de desintoxicación ("desafío semana sin azúcar", "sin gluten", etc.). Por ejemplo, para noviembre de 2016, esta empresa organizó un workshop de cuatro días sobre "comidas energéticas" que incluye las siguientes clases: "introducción a la comida energética", "curación con jengibre", "granos integrales", "cocinar para energizarse".

Estos cursos se anuncian a través del marketing digital (paginas web de la empresa y, sobre todo, redes digitales y aplicaciones de teléfonos celulares). Al igual que en otras esferas de la vida comercial y social en China, en el mercado de la alimentación saludable, las redes y plataformas digitales ocupan un lugar protagónico como escenario de difusión e intercambio de información, imágenes, ideas y opiniones. En estas redes, las imágenes de alimentos y platos circulan con un detallado tratamiento visual y una cuidada puesta en escena, que está en sintonía con la concepción de la comida ampliamente difundida en China que sostiene que los alimentos que son buenos a la vista, también son sabrosos.

Pero en el caso de las imágenes de alimentos considerados como saludables, esta concepción también incorpora elementos relacionados con el bienestar corporal y emocional de las personas. En estas imágenes los alimentos están Ilamados a simbolizar el estado corporal y espiritual de quienes los consumen. Pero las personas que consumen estos productos rara vez aparecen en las imágenes. Los alimentos, bajo la forma de ingredientes y platos preparados, ocupan el centro de las imágenes, mientras que el acto de comer y los comensales están prácticamente ausentes del régimen estético que construye el marketing de la alimentación 
saludable. Considero que esto se debe a que el marketing de la alimentación saludable en Shanghái es ante todo el marketing de los beneficios morales que presentan los productos saludables para quienes los consumen. Por eso es que, en la mayoría de estos establecimientos, el foco está puesto en la estetización y moralización de los productos antes que de los consumidores.

Al igual que otros empresarios vinculados a la alimentación saludable que encontré en mi investigación en Shanghái, Judy actúa como una "emprendedora moral"(13) que busca modificar el universo de normas, valores y prácticas más convencionales asociadas con la alimentación en China. Los cursos que se dictan en su empresa despliegan una pedagogía culinaria que busca transformar los alimentos, la alimentación y el acto de cocinar en un proceso civilizatorio que involucra una redefinición de las ideas y valores sobre el cuerpo y la salud, los gustos y los modales, las relaciones sociales y familiares y el vinculo con el medioambiente, como así también también la relación de las personas con las tradiciones culinarias de su propio país.

\section{NUEVOS CAMPESINOS}

La mayoría de las verduras y hortalizas que se venden en las páginas web de productos orgánicos y las que se consumen en los restaurantes de alimentación saludable en Shanghái provienen de quintas ubicadas en la isla de Chongming, a 100 kilómetros de distancia de Shanghái. Algunas de estas huertas poseen certificaciones nacionales $y$, en menor medida, internacionales, que avalan el carácter orgánico, ecológico o libre de pesticidas y contaminación de sus cultivos y sus campos. Muchas otras cultivan bajo el régimen de "conversión" requerido como instancia previa para la certificación orgánica, que implica un tratamiento especial de la tierra durante al menos tres años para eliminar pesticidas y fertilizantes químicos residuales de plantaciones anteriores. También existen algunas huertas más pequeñas en su volumen de producción que se autodefinen como de "agricultura natural" o "ecológicas", que no aspiran a obtener certificaciones orgánicas porque descreen de la honestidad de los actores involucrados en los procesos de certificación o porque están en desacuerdo con las técnicas de cultivo rotuladas como "orgánicas".

En julio de 2016 pasé un día entero en la isla de Chongming visitando una huerta que se inscribe en este último grupo y que provee de verduras y hortalizas a algunos restaurantes e intermediarios en Shanghái. EI principal responsable de la quinta es Wang, un hombre chino de alrededor de 40 años que dejó su trabajo como empleado calificado en Shanghái para mudarse al campo y dedicarse a la "agricultura natural", una filosofía de cultivos originada en Japón que se basa en el principio de la menor intervención humana sobre las plantaciones. Ocho años atrás, Wang arrendó una casa rodeada de alrededor de 50 hectáreas en Chongming y comenzó un proyecto de agricultura al que luego se sumó Yujing, su actual pareja, quien se encarga de las tareas administrativas y educativas de la huerta. Antes de su "cambio de vida", tal como ella lo definió, Yujing vivía en Shanghái y trabajaba como traductora de inglés, para lo cual se había formado en una prestigiosa universidad china.

Wang y Yujing se autodefinen como "nuevos campesinos" porque, según me dicen, sus ideas y prácticas de cultivo son muy diferentes a las de los "campesinos". Yujing considera que su origen de clase media urbana con formación universitaria no es lo que la diferencia de los campesinos tradicionales que tienen como vecinos en esa isla. Para ella la principal diferencia radica en que ella y Wang respetan la naturaleza. Los viejos campesinos, dice, están acostumbrados a utilizar potentes pesticidas y fertilizantes químicos para acelerar el crecimiento de los cultivos y aumentar su tamaño para obtener mayores ganancias económicas.

Mientras caminamos entre arrozales y plantaciones de zapallitos, berenjenas, papas, aromáticas y morrones, Yujing me 
dice: "cuando los viejos campesinos de la zona vienen acá y ven esto nos dicen que nosotros no cuidamos bien los cultivos, que tenemos todo lleno de bichos y malezas, que los cultivos no son lindos, no son grandes o que tienen formas diferentes". Los campesinos tradicionales, dice, "no nos entienden". También me aclara que lo que ellos hacen no es horticultura orgánica, porque ellos no quieren ni pueden pagar las certificaciones, de cuya veracidad desconfían, ni tampoco se guían por los criterios de las huertas que se presentan como orgánicas pero que, según me dice, son similares a las tradicionales: están todas "limpitas", no tienen bichos ni malezas, utilizan invernaderos, que "son muy poco naturales", para cultivar verduras que son "todas iguales y muy vistosas".

Wang y Yujing viven en una casa grande y vistosa, de dos pisos, muy similar a otras casas que los campesinos de la zona construyeron, en la mayoría de los casos, con aportes de hijos y familiares que mejoraron considerablemente su situación económica trabajando en las ciudades chinas, las cuales vivieron un enorme crecimiento económico en las últimas dos décadas.

Cuando llegué a la huerta, a las 10 de la mañana de un día de semana, Yujing me dice que su casa es un espacio comunitario. Ella y su marido viven en el segundo piso, el único espacio privado de la casa. El primer piso tiene habitaciones que se alquilan para huéspedes que visitan la huerta durante algunas semanas para aprender técnicas de "cultivos naturales" o que dejan Shanghái por un par de días para tener contacto con la naturaleza y aprender rudimentos de horticultura. El día de mi visita había tres huéspedes: una periodista china que hacía tres semanas estaba allí explorando el trabajo de la huerta y haciendo entrevistas como parte de una investigación que la había llevado a conocer quintas orgánicas en todo el país ("hay un boom de las quintas orgánicas en China", me dijo), una joven coreana y dos jóvenes chinos que se habían mudado allí hacía tres meses para aprender técnicas de cultivo natural (ambos de origen de clase media urbana, uno de ellos estudiante de arte, la otra traductora de francés que había dejado su trabajo para "mudarse al campo"). La planta baja de la casa es un espacio enorme que cuenta con una cocina comunitaria, un salón comedor y dos salones pequeños para talleres y reuniones.

En mi visita almorcé y cené con Yujing, Wang, los huéspedes y otros colaboradores de la huerta (tres vecinos de no más de 25 años que se habían criado en las grandes ciudades y habían "regresado al campo" para aprender a trabajar la tierra). Los ingredientes de los platos provenían de la huerta propia o de huertas cercanas con quienes ellos intercambiaban productos: arroz negro, zapallitos, papas, cebollas moradas y de verdeo, ajos, porotos, pimientos, zanahorias, cilantro, nabo, jengibre, tofu casero y fideos caseros. Los métodos de cocción que Yujing había utilizado para cocinar eran rápidos y simples: hervor para el arroz, los fideos, las papas y las legumbres, y saltado en wok para las hojas verdes, los morrones y las cebollas, con el agregado de aceite de sésamo, aceite de girasol, salsa de soja, ajo y jengibre. Todos los alimentos se colocaron en platos en el centro de la mesa para que cada uno de nosotros, los comensales, se sirviera. Algunos platos eran combinaciones simples como papa con cebollas y cilantro o porotos con cebollas. Cada uno de los comensales tenía un plato hondo con arroz que, durante la comida, mezclaba o intercalaba con bocados de los otros platos servidos sobre la mesa.

A la hora de la cena llegó un grupo de alrededor de 15 jóvenes chinos que, según me comentaron, había venido desde una ciudad cercana con la intención de comer "buena comida" en un ambiente rural. El menú previsto era fideos que $\mathrm{Ho}$, la huésped coreana, amasó y cortó enfrente de ellos, y que Yujing cocinó junto con verduras de la huerta salteadas en el wok. Los jóvenes no paraban de tomarle fotos a ellas mientras cocinaban, a los ingredientes y luego a los platos que estaban comiendo. Estaban fascinados con la comida y el lugar en donde estaban. "Hen hao che, hen hao che" (muy delicioso, muy delicioso) repetían constantemente. 
Estos jóvenes forman parte del enorme crecimiento que tuvo en la última década el turismo rural entre las clases medias urbanas chinas. Una modalidad muy expandida del turismo rural es la de los llamados nonjiale, que consiste en familias de campesinos o de "nuevos campesinos" que abren las puertas de sus casas y sus huertas a visitantes que llegan desde las ciudades en búsqueda del contacto con los símbolos emblemáticos del mundo rural: comida rústica y saludable, tradiciones, autenticidad, un entorno natural, animales, trabajo manual y otro ritmo de vida ${ }^{(14)}$.

Esta expansión de la popularidad del turismo rural entre las clases medias urbanas chinas también incluye a personas que viven en las ciudades y alquilan una parcela de tierra en quintas en funcionamiento, deciden qué quieren plantar y contratan los servicios de algún campesino o del propietario de esa quinta para que se encarguen de los cultivos que ellos visitan en días feriados o fin de semana. Yujing me dijo que si bien esta modalidad representa un ingreso adicional para los campesinos, en general, los arrendatarios no están interesados en aprender a cultivar la tierra sino que utilizan sus parcelas como ámbitos de esparcimiento u objeto de consumo donde tomarse fotos para mostrar a sus grupos de amigos y familiares. Ellos perciben la naturaleza y los productos "saludables" de la huerta que pueden Ilevar a sus casas como nuevas fuentes de distinción social.

\section{IDEAS FINALES}

Estas notas exploratorias intentaron mostrar algunos de los significados que adquiere el campo de la alimentación saludable en Shanghái, a partir de las perspectivas de actores e instituciones involucrados en su producción y comercialización. A primera vista, lo que he presentado aquí está en fuerte sintonía con transformaciones globales vinculadas a un creciente interés de los consumidores por conocer sobre los procesos de producción de los alimentos, su origen geográfico y su calidad así como con una mayor preocupación por los impactos sociales y medioambientales de su producción, comercialización y consumo. Se trata de procesos que han sido rotulados como "consumo ético" y que, en términos generales, implican el reconocimiento de las dimensiones políticas involucradas en el acto de consumir y el desarrollo de modalidades "alternativas" de producción y consumo ${ }^{(15)}$.

Sin embargo, como señalan algunos autores, esta mirada sobre el "consumo ético" presenta como problema que se basa en la presunción de que la comida es de antemano ética o no ética, sin prestar atención a cómo la comida, y por extensión las prácticas sociales vinculadas a la comida, se transforman en un hecho ético o no ético, es decir, cómo las prácticas alimentarias se articulan con proyectos ético-morales ${ }^{(16)}$.

La exploración que he presentado en estas páginas deja entrever que la dimensión ética -los sentidos acerca de lo que es correcto o incorrecto, bueno o malo, aceptado o prohibido- de los modelos de alimentación que promueven los escenarios y actores vinculados a la alimentación saludable en Shanghái remiten más a una ética individual con implicancias circunscriptas al plano subjetivo y familiar que a una ética colectiva con implicancias políticas más amplias.

En China, los severos problemas bromatológicos y de contaminación medioambiental han transformado la alimentación, y los temas conexos como salud y nutrición, en un campo político por excelencia. El mercado de la alimentación saludable en Shanghái es claramente una caja de resonancia de estos problemas. Y el creciente éxito comercial de este mercado responde, en buena medida, a las angustias, temores y estrategias de las clases medias y altas respecto de su alimentación. Pero esto exige, desde el punto de vista de los actores involucrados en el mercado de la alimentación saludable, una domesticación de la politicidad de la problemática social que sobrevuela constantemente este campo. Esta domesticación se expresa, principalmente, a través de la estetización de los alimentos y la alimentación, y su vinculación a prácticas individuales y subjetivas 
de construcción de bienestar individual antes que a dimensiones colectivas y políticas.

Así, entendida como una responsabilidad y un estilo de vida individual, la alimentación también implica una redefinición del estatus moral de la persona como individuo. El marketing de la alimentación saludable en Shanghái es, ante todo, el marketing de las promesas de estetización y moralización de los estilos de vida individuales a través del consumo de estos alimentos. Se trata de un mercado que se nutre de dos lógicas sociales que ocupan un lugar central en los modos en que los individuos buscan construir "bienestar" y "calidad de vida" en la China actual: las estrategias para conjurar y paliar en el plano individual y familiar los efectos de la contaminación medioambiental y la búsqueda de distinción social y moral a través del consumo.

\section{REFERENCIAS BIBLIOGRÁFICAS}

1. Yan X. Food safety and social risk in contemporary China. The Journal of Asian Studies. 2012;71(3): 705-729.

2. Klein J. Everyday approaches to food safety in Kunming. The China Quarterly. 2014;214:376393.

3. Wang J. Brand new China: advertising, media and commercial culture. Cambridge: Harvard University Press; 2008.

4. Klein J. Creating ethical food consumers? Promoting organic foods in urban Southwest China. Social Anthropology. 2009;17(1): 74-89.

5. Xinhua Insight: China alerted by serious soil poIlution, vows better protection. Xinhua [Internet]. 17 abr 2014 [citado 12 oct 2016]. Disponible en: http://tinyurl.com/hr33hv5.
6. Jian Y. China's river pollution 'a threat to people's lives'. People.cn [Internet]. 17 feb 2012 [citado 10 oct 2016]. Disponible en: http://tinyurl. com/zajzx42.

7. Anagnost A. The corporal politics of quality (suzhi). Public Culture. 2004;16(2):189-208.

8. Brandtstädter S. Fakes: Fraud, value anxiety and the politics of sincerity. En: Sykes K, (ed). Ethnographies of moral reasoning: Living paradoxes of a global age. Palgrave: New York; 2009.

9. Zhang L. In Search of Paradise: Middle Class Living in a Chinese Metropolis, Cornell University Press; 2010.

10. Chen M, Goodman D, (eds). Middle class China: Identity and behaviour. Cheltenham: Edward Elgar Publishing; 2013.

11. Rofel L. Desiring China: Experiments in neoliberalism, sexuality, and public culture. London: Duke University Press; 2007.

12. Hunter Gatherer [Internet]. c2014 [citado 10 oct 2016]. Disponible en: http://tinyurl.com/jsba3lb.

13. Becker H. Outsider: hacia una sociología de la desviación. Buenos Aires: Siglo XXI Editores; 2009.

14. Park C. Nongjiale tourism and contested space in rural China. Modern China. 2014;40(5):519548.

15. Lewis $\mathrm{T}$, Potter $\mathrm{E}$, (eds). Ethical consumption: A critical introduction. London: Routledge; 2011.

16. Jung Y, Klein J, Caldwell M, (eds). Ethical eating in the postsocialist and socialist world. Berkeley: University of California Press; 2014.

\section{FORMA DE CITAR}

Badaró M. Alimentación saludable en Shanghái: notas exploratorias. Salud Colectiva. 2016;12(4):651-664.

http://dx.doi.org/10.18294/sc.2016.1262 